\title{
TISSUE REPAIR AFTER THE OPERATIONS OF RECESSION AND RESECTION*
}

\author{
BY \\ R. M. INGRAM \\ University Departments of Ophthalmology and Pathology, Manchester
}

THE surgical treatment of squint has passed through many stages, but even the operations of recession and resection are not entirely predictable so far as the endresult is concerned. The search for the magic formula of how many millimetres of surgery correct $x$ degrees of deviation still eludes us. We do not know how the operations work (Knapp, 1958) and, indeed, we may not yet have designed the ideal operations. There seems, however, to be little point in describing new operations (e.g. Worst, 1962) before we know exactly what is wrong with recessions and resections, and why anomalous re-attachments of the muscle to the sclera occur after these operations.

Dieffenbach's operation has been modified many times, but the process whereby the wounds heal has been studied only twice. Lucien Boyer (1842) showed that a muscle which had been tenotomized became re-attached to the sclera and, 90 years later, Carroll and Blake (1932) studied wound healing after recession and resection of the extra-ocular muscles in the rabbit. Their work, however, is open to the following criticisms:

(1) They did not state which muscles were recessed or resected. This is particularly important in the rabbit, because the superior oblique muscle is inserted behind the insertion and underneath the belly of the superior rectus. They did not comment on this, and it is possible that this normal structure was mistaken for the anomalous re-attachments which they described.

(2) They used catgut sutures in only four operations and they did not state what sizes were used. The nature and size of the suture may affect the healing process.

(3) They performed only sixteen recessions and twelve resections, and their observations covered only the period between 4 and 40 days after operation. Furthermore, their resections consisted of resecting a portion from the middle of the muscle-a procedure which would be conducive to the formation of adhesions between the muscle and the sclera behind the muscle insertion.

(4) They did not study the rate at which these wounds healed.

Carroll and Blake found that the muscle was fairly firmly attached to the sclera 10 to 14 days after operation. They found that the recessed muscle often became reattached to the sclera in front of the line to which it was sutured, and that adhesions frequently formed between the resected muscle and the sclera behind the muscle's original insertion. Similar anomalous re-attachments occur in human cases (Berens, 1938; Gifford, 1942) and Carroll and Blake suggested that they were the result of 
haemorrhage at the time of operation. Nutt (1961) had advocated rigorous haemostasis to prevent this.

A histological comparison of the untouched muscle-to-sclera junction in rabbits, monkeys, and man shows that, in both monkeys and man, a well-defined tendon joins the muscle to the sclera. This tendon is not present in rabbits, where the muscle fibres fuse directly with the sclera (Fig. 1).

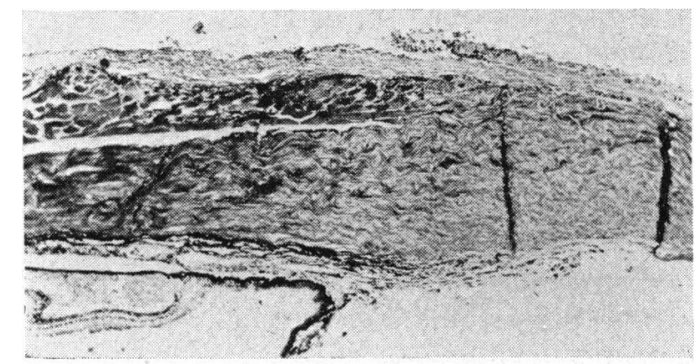

FIG. 1.-Insertion of inferior rectus muscle in the rabbit. Masson stain. $\times 30$.

It is, therefore, reasonable to suppose that the findings after experimental recession and resection operations in rabbits have no direct bearings on these wounds in man.

Nevertheless, so little is known about this problem that in spite of the different structures involved, it seemed right to start at the beginning by repeating and expanding the work of Carroll and Blake. The following plan was therefore adopted:

Recession and resection operations were carried out on the extra-ocular muscles of rabbits and the wounds were examined at $0,1,2,3,4,5,7,10,14,21,28,56$, and 84 days after the operation. The right eye was used in all cases and, on each post-operative day, two eyes were removed for histological study. All the animals were fed on a standard diet containing $14 \cdot 7$ per cent. protein.

\section{Choice of Muscles for Operation}

The anatomy of the rabbit's extra-ocular muscles is shown in Fig. 2. The inferior rectus was recessed $4 \mathrm{~mm}$. to a line just in front of the retractor bulbi muscle, which served as a convenient "marker" when examining the histological sections. The superior rectus muscle was resected $4 \mathrm{~mm}$.

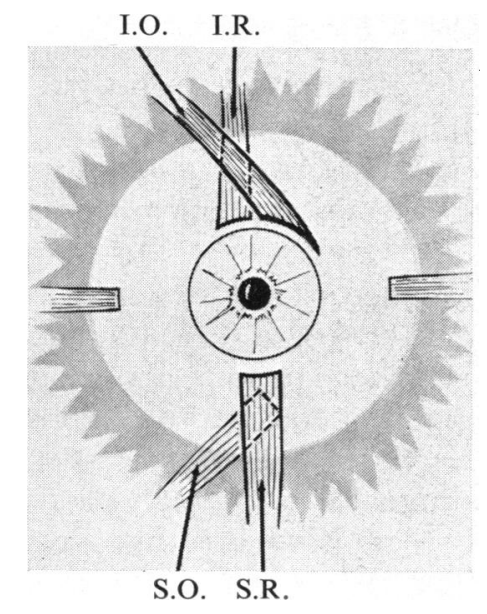

FIG. 2.-Insertions of the extraocular muscles in the rabbit.

I.R. = Inferior rectus

S.R. = Superior rectus

I.O. = Inferior oblique

S.O. $=$ Superior oblique 


\section{Method of Operation}

Each animal was weighed. Anaesthesia was induced with intravenous Nembutal and maintained by the "open-ether" method.

The conjunctiva was opened and each muscle dissected out. One double-armed suture was used to fasten the muscle to the sclera in each operation. A whip stitch was tied round one edge of the muscle $1 \mathrm{~mm}$. from its insertion in the case of a recession and $5 \mathrm{~mm}$. from its insertion in the case of a resection. One end of this suture was passed across the muscle and used to tie a whip stitch around the other border, at a similar distance from the insertion. The muscle was then severed on the distal side of the sutures. The inferior rectus was sutured to the sclera $4 \mathrm{~mm}$. behind the original insertion, and the superior rectus was sutured to the muscle's original insertion. In each case, the suture was tied with a surgeon's knot. The conjunctiva was closed with a "continuous" 6/0 plain catgut suture. No antibiotics or steroids were used at any time. Only one eye became infected and this was excluded from the series.

Two complete series of operations were carried out. Comparable sizes of plain catgut and silk sutures were used ( $3 / 0$ catgut and $2 / 0$ white silk) in order to see if the nature of the suture material affected the healing process.

\section{Preparation of Histological Specimens}

No attempt was made to "fix" the eyes and muscles in situ in the orbit because there is a danger of profuse haemorrhage if the venous sinus is opened. In order to prevent the muscles contracting and coiling upon themselves, time was allowed for rigor mortis to take place by killing the animals on the appropriate day and removing the eye 24 hours later.

A rectangle of cornea and sclera, with the muscle attached, was cut from the eye and placed in a fixative solution (50-50 mixture of 10 per cent. formalin and mercuric chloride). Sections were cut from each of four "levels" across the wound. They were stained with haematoxylin and eosin and Masson's stains.

\section{Catgut Sutures}

\section{Findings}

The process whereby both the recession and resection wounds heal is basically the same, and this is not surprising, since, in both cases, muscle is joined to sclera. On the day after operation, both wounds are oedematous, and there is a profuse infiltration of the whole wound area with polymorphonuclear leucocytes together with a few lymphocytes. Many of the fibres in the anterior $3 \mathrm{~mm}$. of the muscles show signs of being damaged. On the second day, a few fibroblasts can be seen among the necrotic muscle fibres. The inflammatory cells, which now include histiocytes, are collected mainly around the suture (Fig. 3, opposite).

The inflammatory reaction, greatest 2 to 4 days after operation, is more marked in the resection wounds where the stumps of muscle fibres, which remain attached to the sclera, are caught up in the suture.

On the third day, the fibroblasts are more numerous and they are becoming aligned in some sort of order between the muscle and the suture (Fig. 4, opposite). A little fibrous tissue is already being laid down. The inflammatory reaction is almost confined to the surrounds of the suture-a point of considerable importance because it implies that, in the absence of allergic reactions and infection, the inflammatory reaction in an eye after the second post-operative day is probably proportional to the amount of suture material in the wound. There is, by this time, very little inflammatory reaction in the sclera. 


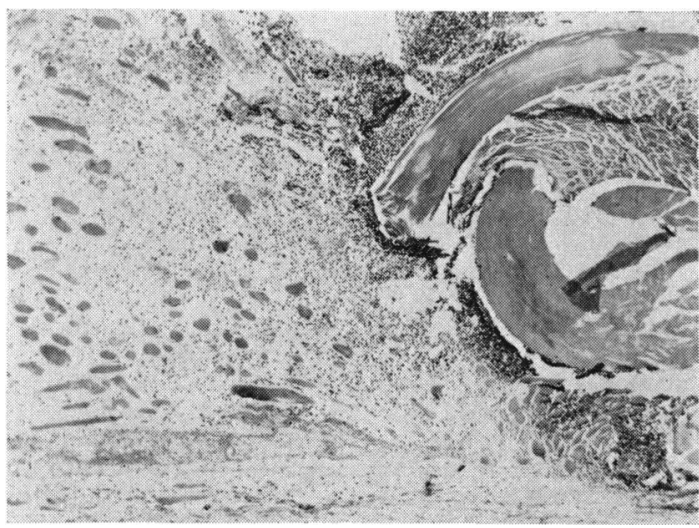

FIG. 3.-Recession Day 2. Inflammatory cells have collected mainly around the suture. Haematoxylin and eosin. $\times 36$.

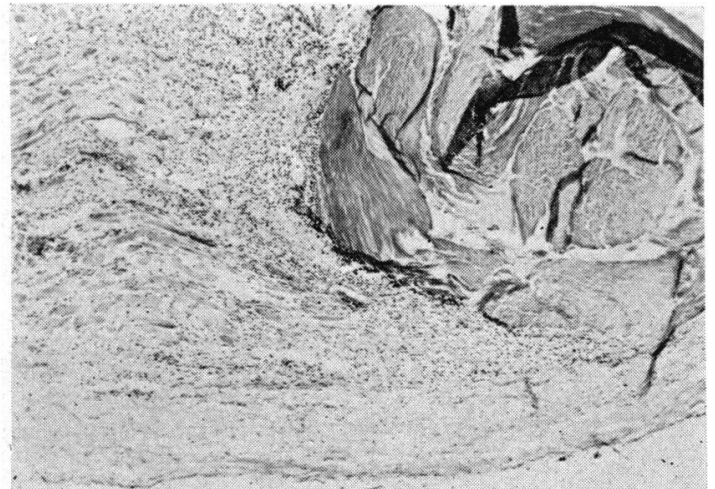

Fig. 4.- Recession Day 3. Organization has started. Haematoxylin and eosin. $\times 36$.

Four days after operation the deposition of fibrous tissue is further advanced and by the fifth day there is a definite fibrous re-attachment of the muscle to the sclera (Fig. 5). There is often a considerable difference between the picture at the centre of a wound and that at the edge of the same wound and between any two wounds examined on the same day. However, fibrous tissue is progressively laid down until the muscle appears to be firmly re-attached to the sclera 10 to 14 days after operation. From the fifth day onwards, interest centres in the distribution of the newly formed fibrous tissue and in the ability of the muscle to grow forwards into the wound area. There are unmistakable signs, in all the sections, that the muscle fibres are regenerating 4 days after operation. This process occurs independently of any signs of haemorrhage, of which there are practically none. Initially, the nuclei of the muscle fibres enlarge and multiply, and then they migrate towards the damaged end of the muscle fibre. Finally, they pass down the sarcolemmal sheath. In one case, new muscle fibres were seen growing forwards as early as the seventh day (Fig. 6), and it is important to note their distribution and position in the fibrous tissue which surrounds the suture.

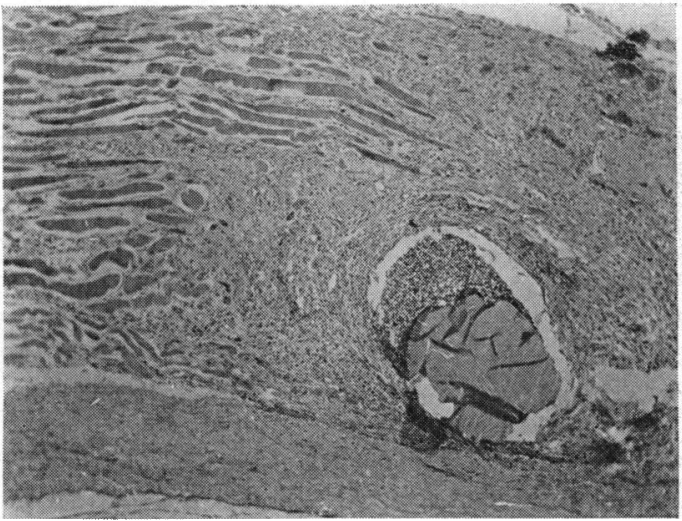

FIG. 5.-Definite fibrous re-attachment of the muscle to the sclera. Haematoxylin and eosin. $\times 36$.

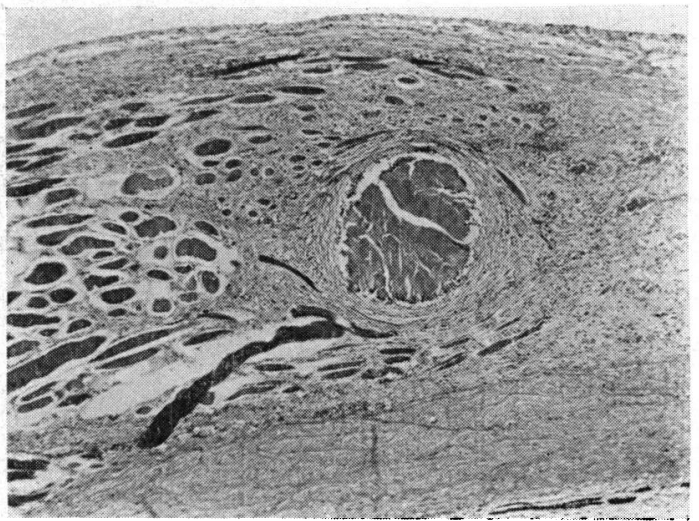

FIG. 6.-Recession Day 7. Muscle fibres can be seen growing forwards around the suture. Haematoxylin and eosin. $\times 36$. 
The fibrous tissue is laid down mainly in concentric rings around the suture. It is also situated between this and the muscle, being arranged in the shape of a "Y" on its side. The deeper arm of this "Y" forms the fibrous attachment of the muscle to the sclera (Fig. 7). In front of the suture, and at the edges of the wounds, the fibrous tissue is arranged somewhat irregularly, gradually fading away. The muscle fibres grow forward, often situated within the rings of collagen fibres that surround the suture.
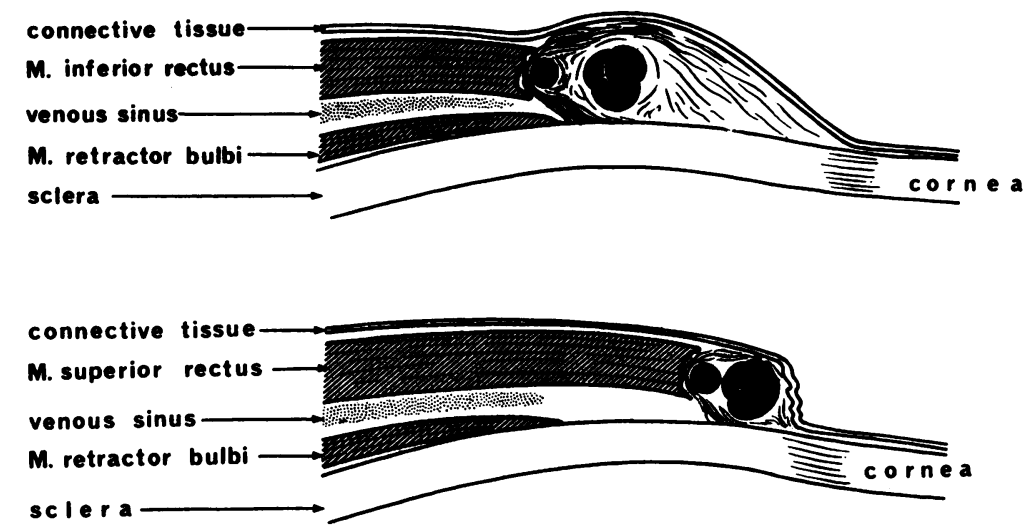

Fig. 7.-Arrangement of the fibrous tissue laid down in the wounds.

By the tenth day the muscle is firmly re-attached to the sclera. There is a neat reattachment at the other edges of the wound, but at the centre there is still a large foreign-body granuloma. The principal difference between the wounds examined 10 and 28 days after operation is the regeneration of the muscle. New muscle fibres have invaded the fibrous tissue, principally where the fibrous tissue is less dense (Fig. 8). Fragments of catgut suture were seen in all the wounds examined 28 days after operation.

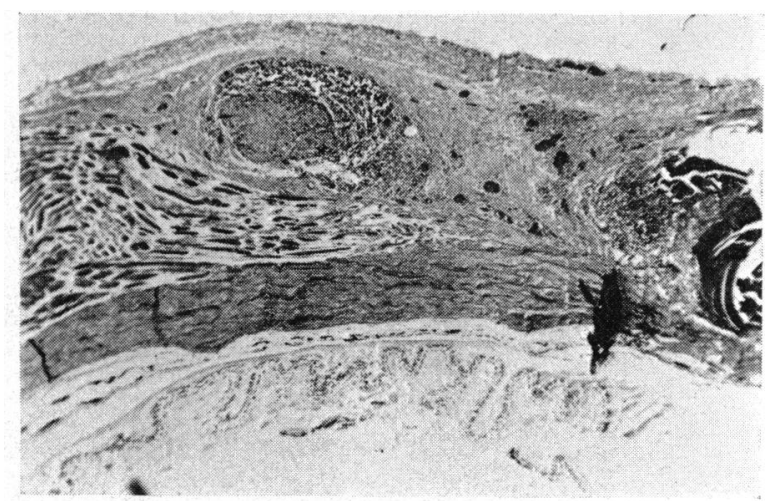

Fig. 8.-Recession Day 28. New muscle fibres have grown forwards underneath the proximal strand of suture. Haematoxylin and eosin. $\times 18$.

There was no sign of the suture 2 months after operation, by which time much of the fibrous tissue had been removed from the wound area, its place being taken by new muscle fibres which have grown forwards. In the recession wounds, the muscle fibres 
have grown right forwards in front of the place where they were sutured (Fig. 9). Whereas a month earlier the resected muscle was joined to the sclera by fibrous tissue over a wide area, much of this fibrous tissue has been removed and the muscle fibres have grown forwards so that there is relatively neat re-attachment at the correct point (Fig. 10).

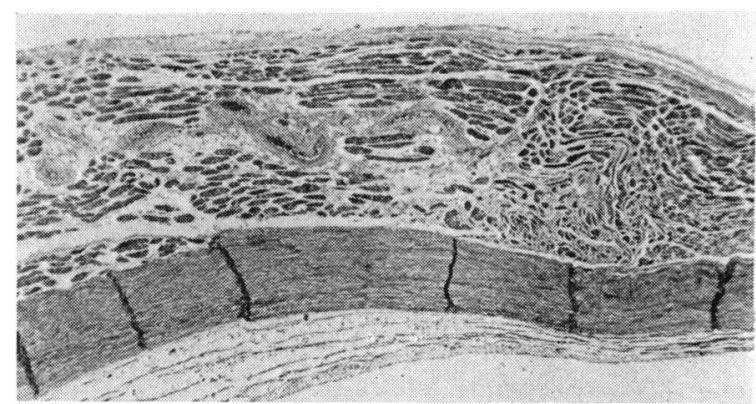

FIG. 9.-Recession Day 56. The muscle fibres have grown right forwards in front of the place on the sclera to which they were sutured. Haematoxylin and eosin. $\times 18$.

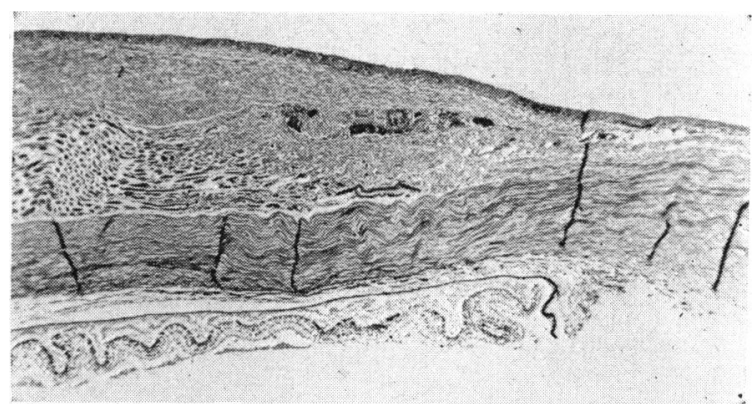

FIG. 10.- Resection Day 56. The muscle is re-attached to the sclera at the site of its original insertion. Haematoxylin and eosin. $\times 18$.

The disappearance of the fibrous tissue and regeneration of the muscle continue until, 3 months after operation, the new insertions of the muscles appear to be almost normal. In one of the two rabbits killed at this time, the recessed muscle was reattached to the sclera approximately at the point to which it was sutured, but in the other animal, the re-attachment was over a wide area extending almost to the original insertion. The area of re-attachment was slightly different in the two resection wounds, but in neither case were there any adhesions between the muscle and the sclera behind the original insertion. In one rabbit the muscle was neatly re-attached slightly in front of this point.

\section{Silk Sutures}

There was no obvious difference between the wounds sutured with catgut and those sutured with silk in the first 10 days after operation. This was surprising since it is often said that catgut excites a more marked inflammatory reaction than silk. This was not apparent until the fourteenth day after operation, when there was also a difference in the type of cells. There were mainly histiocytes around the silk sutures whereas there were polymorphonuclear leucocytes and small mononuclear cells around the catgut (Figs 11 and 12, overleaf). There were no obvious differences between the amount or distribution of the fibrous tissue in the wounds. Regeneration of muscle occurs as it does when catgut sutures are used. 28 days after operation, the catgut suture is obviously being absorbed but the silk suture is relatively little affected by the inflammatory reaction.

Two months after operation, however, there was a distinct difference between the wounds. The catgut suture had been absorbed completely by this time, but the silk suture was quite clearly present, surrounded by histiocytes and fibrous tissue.

There was little change in the recession and resection wounds during the third month after operation. The silk suture was still present in all the four wounds examined at this time. It was partly absorbed from the recession wounds and was being extruded through the conjunctiva in the resection wounds. The fibrous tissue 


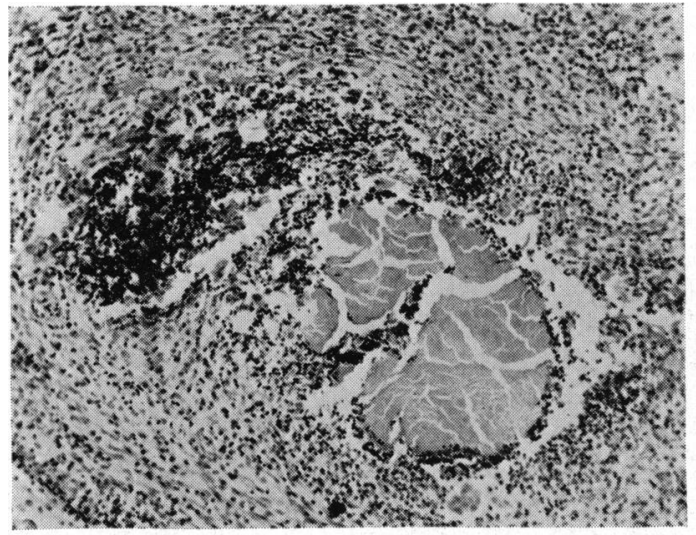

Fig. 11.-Reaction around a catgut suture 14 days after operation. Haematoxylin and eosin. $\times 80$.

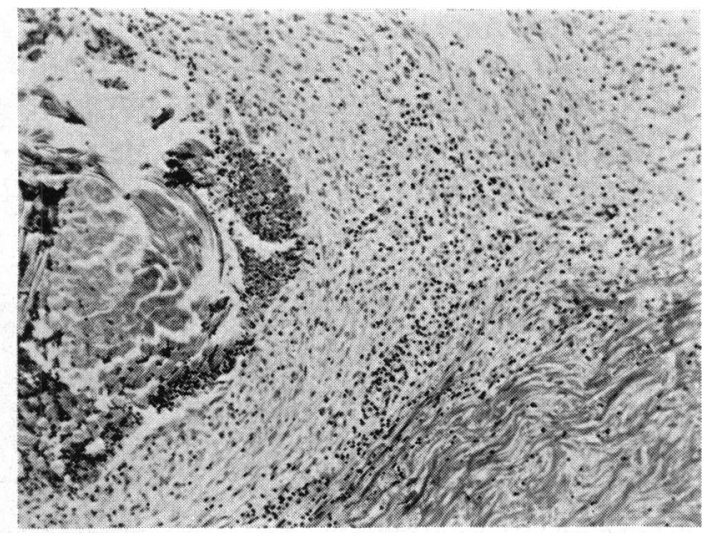

Fig. 12.-Reaction around a silk suture 14 days after operation. Haematoxylin and eosin. $\times 80$.

which was laid down earlier had been partly absorbed and there was evidence that the muscle had grown forwards in front of the suture in both recession wounds. There were no adhesions behind the muscle's original insertion in the resection wounds. Whereas the wounds sutured with catgut appear to be completely healed by this time, this was certainly not the case when silk sutures were used, largely because the silk suture had not been absorbed.

\section{Discussion}

The deposition of new collagen fibres starts on the third day after operation, and there are signs that a definite fibrous re-attachment of the muscle to the sclera is being formed on the fifth day. The muscles appear to be firmly re-attached to the sclera 10 to 14 days after operation. This confirms the findings of Carroll and Blake (1932) and both are confirmed by measurements of the strengths of the union.

The re-attachment of the recessed muscle often extends in front of the line to which the muscle was sutured, as Carroll and Blake found, but there was no confirmation of their finding that extensive adhesions formed between the muscle and the sclera behind the original insertion of a muscle that had been resected. This difference could be explained by the fact that they used silk sutures in most of their operations and did not continue their experiments for longer than 40 days, but there are other possible explanations.

Carroll and Blake attribute the formation of anomalous sites of re-attachment after both operations to haemorrhage at the time of operation. There were no signs of haemorrhage in the sections examined in this investigation. Indeed, haemorrhage was not a feature of the operations. It is not suggested that this was the result of better operative technique, but, almost certainly, it was the result of better anaesthesia. The heads of their rabbits were strapped to an iron block before the anaesthetic was given, and it is possible that this evoked some struggling by the animal and some obstruction of the venous return from the head. Both these factors could cause increased bleeding during operation. In the present series of experiments, anaesthesia was induced with intravenous Nembutal without applying any restraining force to the animals. 
In 1932, it was thought that muscle had a low regenerative ability, but Le Gros Clark (1946) showed that this was not necessarily true. Under certain conditions muscle regenerates very well, and he specifically states that blood clot prevents regeneration.

It is necessary, therefore, to find an alternative reason for the re-attachment of the recessed muscle to the sclera in front of the line to which it was sutured, and also to explain the absence of adhesions between the resected muscle and the sclera behind the muscle's original insertion.

The healing process is basically the same after both operations. Removal of the cellular debris and suture starts within a few hours of the operation, and continues until the suture has been "removed". Regeneration of the connective tissue starts on the second day and is characterized by the deposition of fibrous tissue joining the muscle to the sclera. This re-attachment increases in strength during the next 10 days, and then appears to remain unchanged until a month after operation. Thereafter much of the fibrous tissue disappears from the wound (more slowly when silk sutures are used than when catgut is used). The muscle starts to regenerate on the third day, but the most obvious sign of this process coincides with the disappearance of the fibrous tissue, and the structure and site of the re-attachment appear to alter considerably during the second and third months as a result of these two processes. It seems, therefore, that the natural course of events, after both operations, is for the muscle to become re-attached to the sclera somewhere in front of the point where the muscle fibres remained undamaged by the operation, and that the ability of the muscle to regenerate and grow forward may be the key to where the final re-attachment is situated.

It was, therefore, pertinent to try to find out what factors, in this situation, could aid or impede the forward growth of the regenerating muscle fibres. Le Gros Clark (1946) found that sarcoplasmic outgrowths of the rabbit's tibialis anterior muscle could not penetrate a plasma clot and that muscle fibres did not grow into an area where the muscle had been crushed. Relatively fine strands of fibrous tissue can divert the course of the growing muscle fibre or block its growth altogether if they lie across its path. On the other hand, he found that, when a muscle was devascularized, the fibroblastic reaction was not so dense and the growing muscle fibres were easily able to penetrate it. The muscle fibres then grew down inside newly constructed endomysial tubes formed by fibroblasts invading the endomysial spaces and reinforcing, or reconstructing the sarcolemmal sheaths around the old necrotic muscle fibres. It seems, therefore that fibroblastic activity can aid or impede the forward growth of the regenerating muscle.

There is no doubt that, in many of the sections examined here, fibrous tissue had blocked the growth of muscle fibres. On the other hand, it is interesting to note the presence of muscle fibres in the whorls of fibrous tissue surrounding the suture (Fig. 6), and it is tempting to suggest that a regular arrangement of the collagen fibres in an antero-posterior direction forms an easy path along which the muscle fibres can grow forwards. The arrangement of the muscle fibres that have grown forwards 2 months after both recession and resection operations supports this suggestion

In this series of operations, one double-armed suture was used to fasten the muscles to the sclera and it is evident (Fig. 13, overleaf) that two strands of suture pass right across the wound in front of the free ends of the muscle fibres. Much of 
the fibrous tissue that is deposited in the wounds is laid down in whorls around the suture and is, therefore, arranged regularly in an antero-posterior direction.

There is, furthermore, an interesting similarity between the arrangement of muscle fibres that have grown forwards in front of the suture and that of the necrotic fibres seen in the same situation (Fig. 14) 4 days after operation. This suggests that the sarcolemmal sheaths of the latter have been utilized by the regenerating muscle fibres.

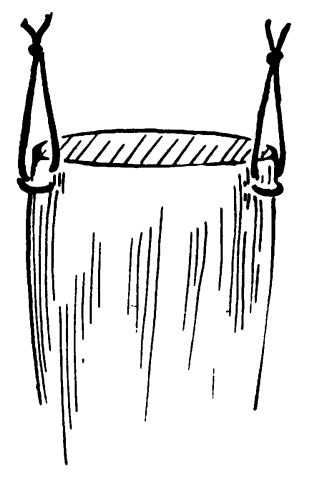

(i)

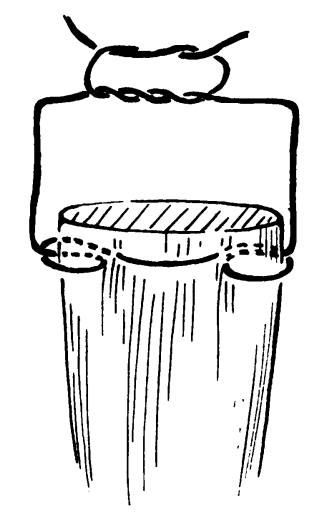

(ii)

FIG. 13.-Position of the sutures in the wound.

(i) Two separate sutures.

(ii) One single-armed suture.

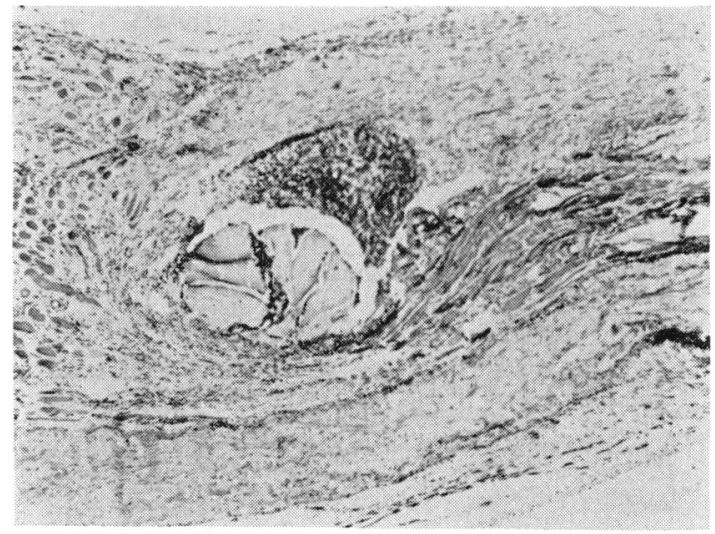

FIG. 14.-Recession Day 4. Necrotic muscle fibres in front of suture. Haematoxylin and eosin. $\times 36$.

In the belief that the ability of the muscle fibres to grow forwards is related to the arrangement of the fibrous tissue that is deposited in the wounds, and that this, in turn, is largely governed by the position of the sutures in the wound, I thought it would be interesting to see what happened when two single-armed sutures were used to fasten the extreme edges of the muscle to the sclera (Fig. 13). In this case, it is evident that there is no suture passing across the wound in front of the free ends of the muscle fibres. Very fine sutures were used in order to reduce the amount of fibrous tissue deposited.

\section{Factors affecting the Forward Growth of the Regenerating Muscle}

Two rabbits were operated upon. A bilateral recession of the inferior rectus muscles was performed on each animal. Two single-armed $5 / 0$ nylon sutures fastened the extreme edges of the muscle to the sclera $4 \mathrm{~mm}$. behind the original insertion of the right eye, and two singlearmed 6/0 plain catgut sutures were used in a similar manner on the left eye. One animal was killed 10 days after the operation and the other animal 18 days later. The eyes were removed exactly as before. Ten serial sections were cut from one edge of each wound (thereby including the suture) and another ten serial sections from the centre of each wound.

The appearance of the wounds 10 days after operation were as expected; viz. the fibrous tissue was laid down round the suture as before but there was less of it, and, in the centre of the wounds, there was comparatively little fibrous tissue (Fig. 15, opposite). There were signs of muscle regeneration, but the muscle had not grown forwards beyond where it was sutured. The two wounds examined 28 days after operation differed from this in only one respect-the $6 / 0$ catgut suture had been absorbed. 


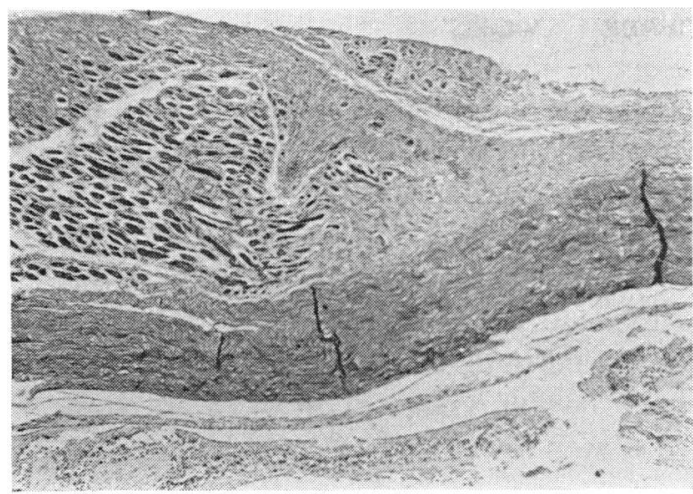

FIG. 15.-Recession Day 10. The muscle has not grown forwards in front of the place to which it was sutured. Haematoxylin and eosin. $\times 36$.

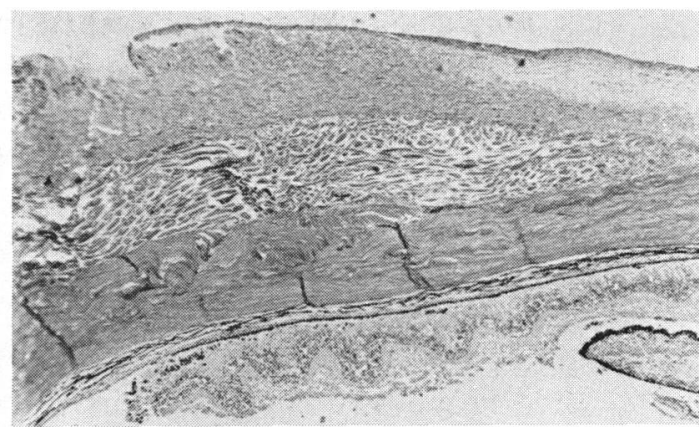

Fig. 16.-Resection Day 56. Extensive adhesions between the muscle and the sclera behind the original site of insertion of the muscle. Haematoxylin and eosin. $\times 36$.

The experiment appeared to show that this method of suturing resulted in the recessed muscle becoming re-attached where it should do, and that the muscle had been prevented from growing forwards.

As this required confirmation three more rabbits were operated upon. In each case, the right inferior rectus was recessed $4 \mathrm{~mm}$. and the right superior rectus was resected $4 \mathrm{~mm}$. Two single-armed sutures were used to suture the muscle to the sclera exactly as above. $5 / 0$ nylon sutures were used in two animals and 6/0 catgut was used in the third. All three animals were killed 2 months after operation, and ten serial sections were cut from each of six levels across each wound. The muscle was found to be firmly attached to the sclera in all cases. The recessed muscle had not regenerated in front of the line to which it was sutured in either of the eyes in which 5/0 nylon sutures were used. However, in the eye in which 6/0 catgut was used, the muscle had grown right forwards in the centre of the wound and was reattached approximately at the original insertion, there being no adhesions between the muscle and the sclera behind this point. There was no obvious reason for the different result in this last case. All three resection wounds showed adhesions between the muscle and the sclera for 3 to $4 \mathrm{~mm}$. behind the original insertion (Fig. 16)-the opposite of what was found when a single double-armed suture was used. This was interesting because muscle necrosis initially extended for 3 to $4 \mathrm{~mm}$. behind the wound. It is possible that, in the absence of an orderly deposition of fibrous tissue to aid the forward growth of the muscle, the muscle fibres made abortive attempts at regeneration and grew for short distances in all directions, thus forming the adhesions.

\section{Conclusions}

The key to the final site of the re-attachment of the muscle to the sclera after recession and resection lies in the ability of the tissues to regenerate.

These present findings offer an alternative to haemorrhage as the explanation of anomalous sites of re-attachment. It is suggested that the muscle will regenerate and grow forwards unless it is prevented from doing so. Furthermore, it is likely that the arrangement of the fibrous tissue deposited in the wound can either aid or impede this process. Since the fibrous tissue is laid down mainly around the suture, it is suggested that the method used to suture the muscle to the sclera indirectly contributes, to some degree, towards the presence or absence of anomalous re-attachments. 
The muscle should be prevented from growing forwards after recession, but the orderly forward growth of the muscle after resection would minimize or prevent the formation of adhesions between the muscle and the sclera behind its original insertion. On this basis, it might be necessary to use two separate sutures in recession and one double-armed suture in resection.

All these experiments have been carried out in rabbits where the muscle is joined directly to the sclera. In man (and monkeys) a fibrous tendon joins the muscle to the sclera and, therefore, unless a large resection is performed, the wound involves the union of fibrous tissue to the sclera. These experiments should, therefore, be repeated in monkeys and attention directed towards the regeneration of the tendon and the factors that affect it. It would be reasonable to use different methods of suturing in the initial experiments.

The nature of the suture material, whether catgut or silk, does not materially affect the final site of re-attachment. There is no apparent difference in the inflammatory reaction around catgut and silk sutures during the first 10 days after operation. It is very likely that, in the absence of allergic reactions or infection, the inflammatory reaction in an eye after the second post-operative day is proportional to the amount of suture material in the wound.

I wish to thank Mr. O. M. Duthie and Prof. A. C. P. Campbell for their advice and support throughout the whole of this work. I also wish to thank Dr. A. Stanworth for discussing various aspects of the investigation.

The operations were carried out in the University Department of Pathology at Manchester University and I wish to thank all the staff for their help; in particular Mr. H. Purvis for his skill in anaesthetizing the animals, Mrs. G. Savill for preparing the microscope slides, and Mr. H. Mowat for the photographs of the slides.

Finally, I wish to thank the Research Grants Committee of the United Manchester Hospitals for providing the financial resources for this work.

\section{REFERENCES}

Berens, C. (1938). Amer. J. Ophthal., 21, 536.

BOYER, L. (1842). "Recherches sur l'opération du strabisme". Germer-Baillière, Paris.

Carroll, F. D., and Blake, E. M. (1932). Arch. Ophthal. (Chicago), 8, 711.

Clark, W. E. Le Gros (1946). J. Anat., 80, 24.

GifFORD, S. R. (1942). Arch. Ophthal. (Chicago), 27, 443.

KnaPP, P. (1958). "'Strabismus Ophthalmic Symposium II”, ed. J. H. Allen. Mosby, St. Louis. NutT, A. B. (1961). Trans. ophthal. Soc. U.K., 81, 757.

Worst, J. G. F. (1962). Amer. J. Ophthal., 53, 676. 